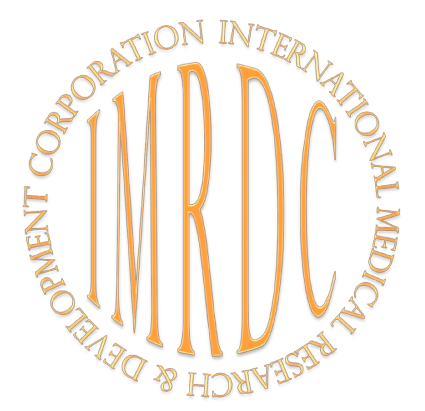

\title{
External Causes in the Structure of Premature Mortality in the Republic of Sakha (Yakutia)
}

\author{
Albina A. Ivanova, $\mathrm{PhD}, \mathrm{ScD}^{*}$; Alexander F. Potapov, $\mathrm{PhD}, \mathrm{ScD}$; \\ Dmitriy V. Bosikov, PhD; Alkviad V. Bulatov, PhD; Tatyana S. Makarova, PhD \\ M.K. Ammosov North-Eastern Federal University \\ Yakutsk, the Republic of Sakha (Yakutia), Russia
}

\begin{abstract}
The purpose of this survey was to study the rate, trends and patterns of mortality from external causes in the Republic of Sakha (Yakutia) $[\mathrm{RS}(\mathrm{Y})]$. A retrospective analysis of statistical data on mortality rate of the population in Yakutia in the period between 1990 and 2017 was carried out.

The results obtained suggest that the population mortality pattern in Yakutia consists of a high proportion of losses from external causes in young age groups. Suicides dominate the structure of external causes of death in Yakutia (20.7\% in 2017), followed by homicides $(13.6 \%)$, cold temperature exposures $(11.4 \%)$ and road traffic accidents $(8.7 \%)$. The annual loss of the working-age population in RS(Y) makes up over $40 \%$ in the total number of deaths. In the structure of the causes of mortality of the working-age population during the entire study period, accidents, poisonings and injuries ranked first, followed by circulatory system diseases and neoplasms. Thus, the main trends that have a negative impact on the creation of the workforce system in $\mathrm{RS}(\mathrm{Y})$ are as follows: the high mortality rate of the working-age population of both sexes; the overmortality of working-age men; the prevalence of preventable causes of death of an exogenous nature (accidents, poisonings, injuries); and an increased share of retirement-age people, resulting in an increased demographic load on the able-bodied population.(International Journal of Biomedicine. 2019;9(1):75-79.)
\end{abstract}

Key Words: premature mortality $\bullet$ working-age population $\bullet$ external causes $\bullet$ suicide $\bullet$ Far North

\section{Abbreviations}

MR, mortality rate; BR, birth rate; RNI, rate of natural increase; RS(Y), the Republic of Sakha (Yakutia); WA, working age

\section{Introduction}

The Republic of Sakha (Yakutia) $[\mathrm{RS}(\mathrm{Y})]$ is one of the regions of the Russian Federation (RF) with special characteristics. Among the constituent entities of RF, Yakutia ranks first by area $\left(3,103.2 \mathrm{~km}^{2}\right)$, whereas by density of the population it is $83 \mathrm{rd}$ out of 85 constituent entities $\left(0.3\right.$ people per $\left.1 \mathrm{~km}^{2}\right)$. It has harsh climatic conditions, with $90 \%$ of the territory not having all-yearround access by transport.In the regional ranking of the Far Eastern Federal District, $\mathrm{RS}(\mathrm{Y})$ has the highest birth rate $(\mathrm{BR})$ and rate of natural increase (RNI), and the lowest mortality rate (MR) (Table 1).

*Corresponding author: Prof. Albina A. Ivanova, PhD, ScD. M.K. Ammosov North-Eastern Federal University, Yakutsk, the Republic of Sakha (Yakutia),Russia.E-mail: iaa_60@mail.ru
However, the increase in the population of Yakutia became relatively steady as late as in 2015. Previously, in 1990-2014, the population in RS(Y) decreased by $14 \%$, or over 156 thousand people (from 1,111.5 to 954.8 thousand people) (Fig.1).

The decline in the population due to migration was about $27 \%$, with the largest outflow of the population observed in the first half of the 1990s, resulting from stagnation in the mining industry. The same period witnessed the beginning of an increase in MR of the population. In general, the demographic indicators followed a negative trend: The total mortality increased by $21 \%$ from 6.7 per 1,000 population in 1990 and reached 8.1 in 2017 . BR decreased by $26.5 \%$ (from 19.6 to 14.4 per 1,000 population); RNI decreased by $50.1 \%$ (from 12.8 to 6.3 per 1,000 population) (Fig. 2). 
Table 1.

Medical-demographic indicators of the regions of the Far Eastern Federal District in 2017 (per 1,000 population)

\begin{tabular}{|l|c|c|c|}
\hline \multicolumn{1}{|c|}{ Region } & $\begin{array}{c}\text { Birth } \\
\text { rate }\end{array}$ & $\begin{array}{c}\text { Mortality } \\
\text { rate }\end{array}$ & $\begin{array}{c}\text { Rate of } \\
\text { natural } \\
\text { increase }\end{array}$ \\
\hline Russian Federation & 11.5 & 12.4 & -0.9 \\
\hline Far Eastern Federal District & 12.1 & 12.1 & 0 \\
\hline Sakha Republic (Yakutia) & 14,4 & 8,1 & 6,3 \\
\hline Kamchatka Krai & 11.8 & 11.0 & 0.8 \\
\hline Primorsky Krai & 10.9 & 13.2 & -2.3 \\
\hline Khabarovsk Krai & 12.0 & 13.0 & -1.0 \\
\hline Amur Oblast & 11.8 & 13.4 & -1.6 \\
\hline Magadan Oblast & 10.9 & 11.3 & -0.4 \\
\hline Sakhalin Oblast & 12.9 & 12.0 & 0.9 \\
\hline Jewish Autonomous Oblast & 11.7 & 13.2 & -1.5 \\
\hline Chukotka Autonomous Okrug & 13.2 & 9.1 & 4.1 \\
\hline
\end{tabular}

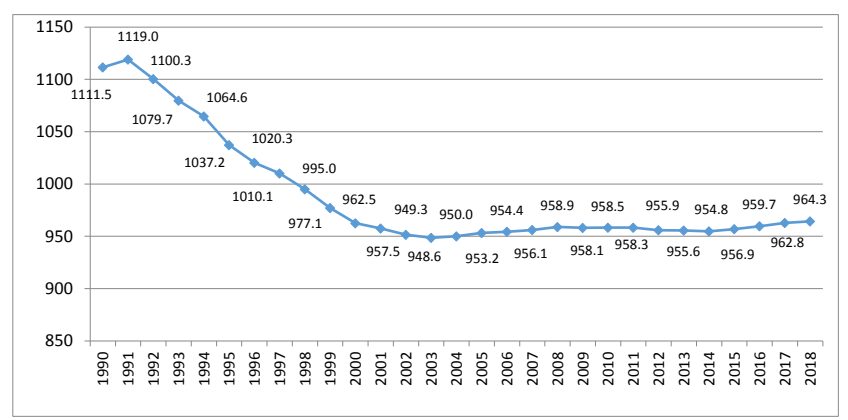

Fig. 1. The population trend in RS(Y) (as of beginning of the year, thousand people).

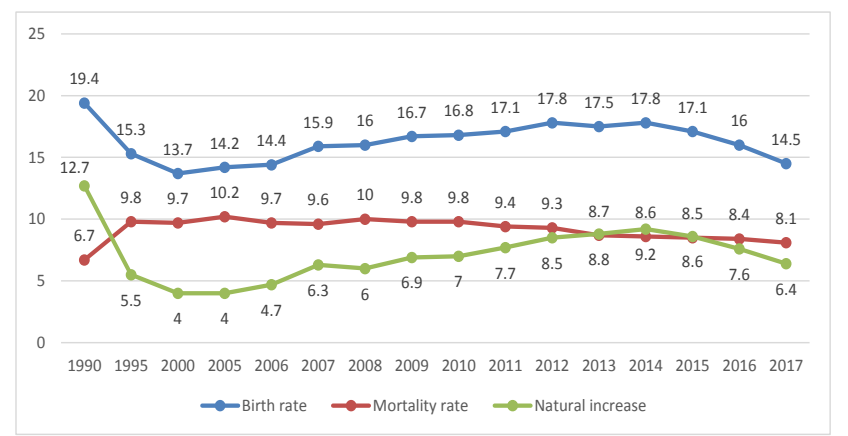

Fig. 2. Trends in $B R, M R$ and $R N I$ of the population in $R S(Y)$ in 1990-2017 (per 1,000 population).

$\mathrm{MR}$ is one of the main indicators characterizing the level of socio-economic development and well-being of the territories, the state of public health, and the availability and quality of the medical care provided. The regions of RF are characterized by diverse climatic, economic, social, and environmental conditions, and by age composition and pronounced territorial features of MR of the population. ${ }^{(1-3)}$ The study and identification of preventable causes of death in certain regions can help reduce MR and provide the framework for targeted regional programs with an impact on the key factors responsible for MR of a region's population from certain causes.

A comprehensive analysis of the state of health of the population in SR(Y), its trends in 1990-2017 and the study of trends and forecasts of the republic's future, made it possible to identify similarities in the ongoing processes compared to other regions of Russia (high mortality, morbidity, chronicity of pathologies, disability; a slow growth in life expectancy), and certain patterns of pathology formation in the Far North, primarily related to the socio-economic and climaticgeographic living conditions of the population.

The time range 1990-2017 saw two periods of increased MR in RS(Y): The first was 1990-1995, with the growth rate at $46 \%$, from 6.7 to $9.8 \%$; the second was $2000-2005$, with the growth rate at $5 \%$, from 9.7 to $10.2 \%$. Subsequently, after a period with the stabilized indicator at 9.3-9.8\%, the rate started decreasing in 2013 and went down to 8.1\%o in 2017 (Fig.1).

In the period between 1990 and 2014, a high level of premature mortality in young age groups from external causes made a distinguishing pattern of the mortality in SR(Y). Human losses due to injuries and poisoning ranked first in the structure of mortality of children and able-bodied persons and accounted for $65 \%$ in the age group from $1-14$ year olds, $91 \%$ in the age group of 15-17 year olds, and 37\% in the working-age group. ${ }^{(4)}$

The purpose of this survey was to study the rate, trends and patterns of mortality from external causes in SR(Y).

\section{Materials and Methods}

A retrospective analysis of statistical data on MR of the population in Yakutia in the period between 1990 and 2017 was carried out. The sources of information were the data from the Territorial Office of the Federal State Statistics Service (Rosstat) in SR(Y), medical certificates of death (form 106/y02), and reports of forensic medical examinations; for fatal traffic injuries, the data from the official site of Traffic Police of Russia (stat.gibdd.ru). The survey was conducted with the use of statistical, analytical, and mathematical methods, as well as methods of comparative analysis.

\section{Results and Discussion}

Among the main causes of mortality of the population in the republic, external causes constantly ranked second after circulatory system diseases in the period 1990-2014, moving to the third position after neoplasms in 2015-2017. However, the statistics indicate a continuing problem with the level of human losses in RS(Y) from external causes. In 1990, MR from this category of causes was 166.3 cases per 100,000 population; in 1995 it reached a maximum value of 257.7; and then it gradually decreased to 130.0 per 100,000 population in 2017 (by 49.6\%). Nevertheless, this level is still quite alarming and is $27.2 \%$ higher than the national average (94.6 per 100,000 population) (Fig. 3).

According to Rosstat, suicides dominate the structure of external causes of death in RS(Y) (20.7\% in 2017), followed by homicides $(13.6 \%)$, cold temperature exposures $(11.4 \%)$ and road traffic accidents $(8.7 \%)$. 


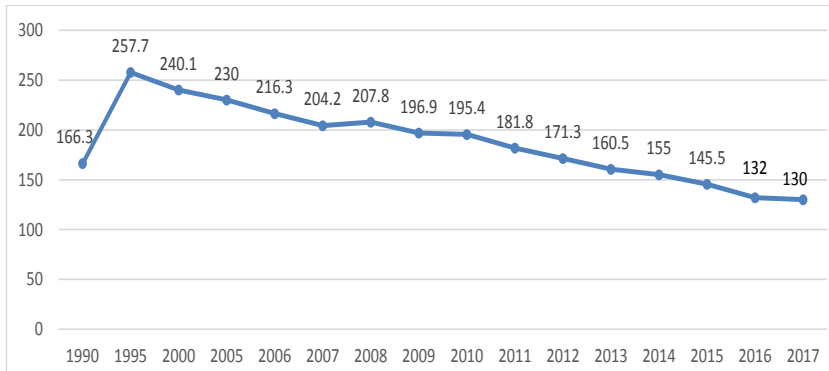

Fig. 3. The trend in mortality from external causes in $R S(Y)$ in 1990-2017 (per 100,000 population).

In the violent death indicators trend in 1990-2017, the years 2000-2005 were particularly unfavorable, when suicide and homicide rates reached the highest levels, almost twice the figures of 1990-1994, and the suicide rate was over 2.5 times higher than the critical parameters defined by WHO experts (20 suicides per 100,000 population) (Fig.4).

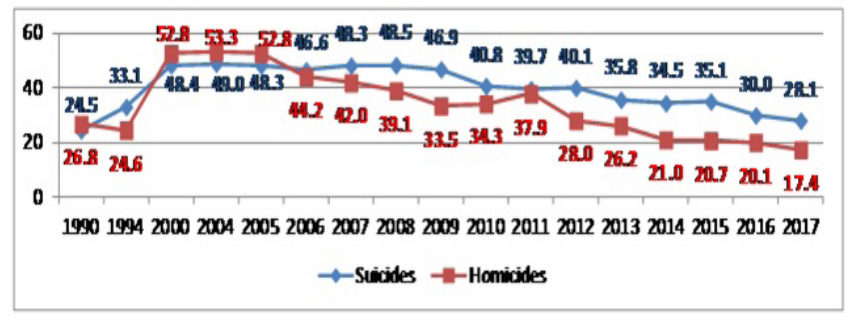

Fig. 4. Violent death indicators trend in RS(Y), 1990-2017 (per 100,000 population).

Almost throughout the study period, the rates of violent deaths in RS(Y) significantly exceeded those of RF and the Far Eastern Federal District. Despite a significant improvement of the situation in 2017, compared to the 2000 data (a decrease in suicide mortality by $42 \%$, homicide - by $67 \%$ ), the situation is still unfavorable. In 2017 , MR from suicide (28.1 per 100,000 population) was $51 \%$ higher than the average in Russia (13.7) and 35\% higher than in the Far Eastern Federal District (18.2). MR from homicides in Yakutia (17.4 per 100,000 population) was almost 3 times higher than the average in Russia (6.0) and 28\% higher than that in the Far East Federal District (12.5) (Table 2 ).

Table 2.

Mortality from suicides and homicides in RF, Far Eastern Federal District (FEFD) and RS(Y) in 2000-2017 (per 100,000 population)

\begin{tabular}{|l|l|l|l|l|l|l|l|l|l|l|l|l|l|}
\hline & 2000 & 2005 & 2006 & 2007 & 2008 & 2009 & 2010 & 2011 & 2012 & 2015 & 2016 & 2017 \\
\hline Mortality from suicides \\
\hline RF & 38.8 & 32.2 & 30.1 & 29.1 & 27.1 & 26.5 & 23.4 & 21.8 & 20.8 & 17.5 & 15.6 & 13.7 \\
\hline FEFD & 49.9 & 42.7 & 40.2 & 40.4 & 38.2 & 35.4 & 34.0 & 31.8 & 30.8 & 24.9 & 19.7 & 18.2 \\
\hline RS(Y) & 48.4 & 48.3 & 46.6 & 48.3 & 48.5 & 46.9 & 40.8 & 39.7 & 40.1 & 35.1 & 30.0 & 28.1 \\
\hline Mortality from homicides \\
\hline RF & 28.0 & 24.9 & 20.2 & 17.9 & 16.7 & 15.1 & 13.3 & 11.7 & 10.8 & 8.0 & 7.0 & 6.0 \\
\hline FEFD & 45.2 & 44.0 & 35.9 & 33.4 & 31.5 & 28.4 & 25.6 & 23.6 & 21.7 & 16.2 & 14.4 & 12.5 \\
\hline RS(Y) & 52.8 & 52.8 & 44.2 & 42.0 & 39.1 & 33.5 & 34.3 & 27.9 & 28.0 & 20.7 & 20.1 & 17.4 \\
\hline
\end{tabular}

There is a generally recognized link between the prevalence of alcoholism among the population and the violent death rate. Alcohol is present in the blood of every second suicide, in 2 out of 3 killed and in 3 out of 4 murderers. ${ }^{(5)}$ According to the Ministry of the Interior of Yakutia, intoxicated people account for $90 \%$ of homicides and $42 \%$ of suicides in RS(Y). In 2017, MR from accidental alcohol poisoning was 8.5 per 100,000 population, while in RF this figure was 4.6 per 100,000 population, and in the Far East Federal District - 3.3.

Cold injuries are another significant problem cause of mortality in the regions of the Far North. In the natural climatic conditions of Yakutia, where the cold season lasts for 7 months of the year with the average winter temperature at $-35-40^{\circ} \mathrm{C}$, mortality due to cold temperature exposures requires serious attention.

The analysis of statistical data revealed that more people die annually in Yakutia from cold temperatures than in road traffic accidents (Table 3).

According to Rosstat, in the period between 2011 and 2017,918 people died as a result of road traffic accidents, and $21.8 \%$ more $(1,118)$ than that as a result of extremely cold temperature exposures. In 2017, MR from cold injury was 15.3 per 100,000 population, while from road traffic accidents, 11.6 per 100,000 population.

People of working age accounted for the largest share in the number of dead (over 79.1\%), including $78.3 \%$ of men aged between 16 and 60 years and $21.7 \%$ of women aged between 16 and 54 years (Table 4).

The age structure of the population of $\mathrm{RS}(\mathrm{Y})$ is dominated by the working-age category $(58.1 \%$ as of January $1,2018)$, with the proportion of persons under the working age at $24.9 \%$, and those over the working age at $17.0 \%$. During the study period, the number of people over the working age almost doubled (from 87.9 to 164.3 thousand), whereas the number of able-bodied persons decreased by $16.1 \%$, children and adolescents by $32.7 \%$ (Table 5 ).

However, the aging process in Yakutia is much slower due to the high rate of premature deaths, especially of the male population. A high MR of working-age people has a particularly negative impact on reproduction in Yakutia, the age and sex composition of the population and the creation of the workforce system. The annual loss of the working-age population in $\mathrm{RS}(\mathrm{Y})$ makes up over $40 \%$ in the total number of deaths. Over the past 5 years, the economically active population has decreased by 34,000 (5.5) due to increased mortality and permanent migration. In the structure of the causes of mortality of the working-age population during the entire study period, accidents, poisonings and injuries ranked first, followed by circulatory system diseases and neoplasms.

According to the 2017 data, able-bodied persons accounted for $88 \%$ in the number of violent deaths, including $79.4 \%$ of men and $20.6 \%$ of women. Able-bodied persons accounted for $85.8 \%$ in the number of suicide deaths, and $91.4 \%$ in homicide deaths. Of those who died from cold temperature exposure, $79.1 \%$ were able-bodied persons (78.3\% of men and $21.7 \%$ of women) (Table 4 ). In addition, able-bodied citizens accounted for $76.2 \%$ in the number of those who died due to alcohol abuse. 
Table 3.

The number of dead in road traffic accidents and due to cold temperature exposures in 2011-2017

\begin{tabular}{|c|c|c|c|c|c|c|c|c|c|c|c|c|c|c|c|c|}
\hline \multirow[b]{2}{*}{ 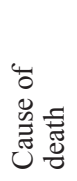 } & \multicolumn{2}{|r|}{2011} & \multicolumn{2}{|r|}{2012} & \multicolumn{2}{|r|}{2013} & \multicolumn{2}{|r|}{2014} & \multicolumn{2}{|r|}{2015} & \multicolumn{2}{|r|}{2016} & \multicolumn{2}{|r|}{2017} & \multicolumn{2}{|r|}{ Total } \\
\hline & 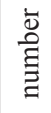 & $\begin{array}{c}\text { per } 100,000 \\
\text { population }\end{array}$ & $\begin{array}{l}\dot{\Xi} \\
\stackrel{\Xi}{\Xi} \\
\Xi\end{array}$ & $\begin{array}{c}\text { per } 100,000 \\
\text { population }\end{array}$ & $\begin{array}{l}\dot{\bar{D}} \\
\stackrel{\Xi}{\Xi} \\
\Xi\end{array}$ & $\begin{array}{c}\text { per } 100,000 \\
\text { population }\end{array}$ & 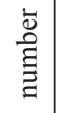 & $\begin{array}{c}\text { per } 100,000 \\
\text { population }\end{array}$ & 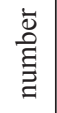 & $\begin{array}{c}\text { per } 100,000 \\
\text { population }\end{array}$ & 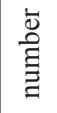 & $\begin{array}{c}\text { per } 100,000 \\
\text { population }\end{array}$ & $\begin{array}{l}\dot{\bar{D}} \\
\stackrel{\Xi}{\Xi} \\
\Xi\end{array}$ & $\begin{array}{c}\text { per } 100,000 \\
\text { population }\end{array}$ & 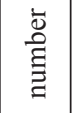 & $\begin{array}{l}\text { per } 100,000 \\
\text { population }\end{array}$ \\
\hline 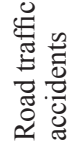 & 157 & 16.4 & 134 & 14.0 & 156 & 16.3 & 140 & 14.6 & 119 & 12.4 & 100 & 10.4 & 112 & 11.6 & 918 & 13.7 \\
\hline 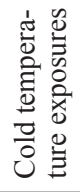 & 195 & 20.4 & 164 & 17.6 & 150 & 15.7 & 158 & 16.5 & 145 & 15.1 & 159 & 16.5 & 147 & 15.3 & 1,118 & 16.7 \\
\hline
\end{tabular}

Table 4

The number of dead due to cold temperature exposures in 2011-2017 by main age groups

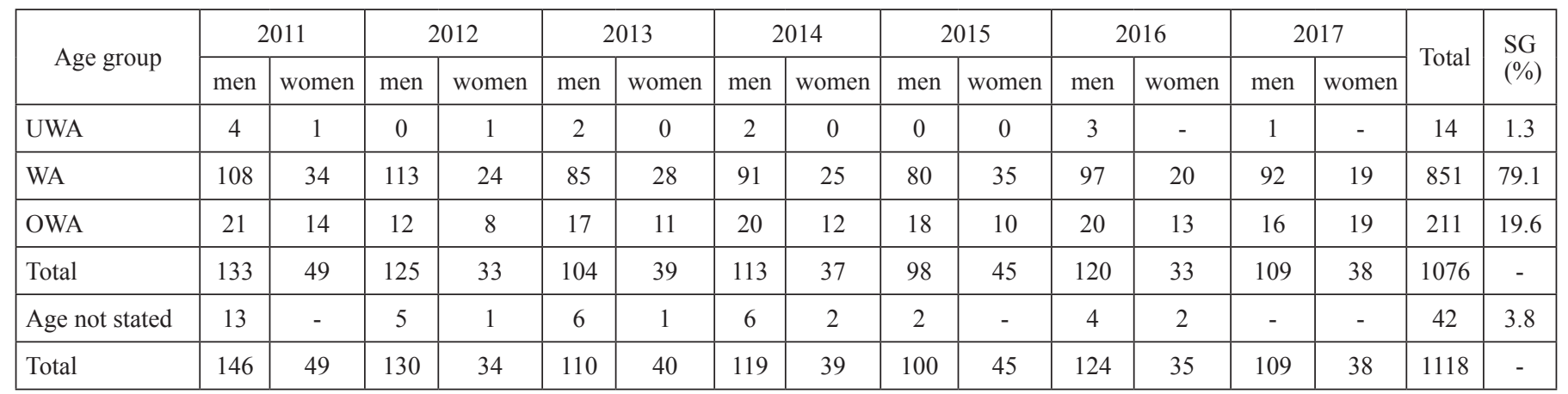

UWA - under working age; OWA- over working age; UWA - 0-15 years; working age: men - 16-59 years, women - 16-54 years; OWA: men - 60 years and up, women - 55 years and up.

Table 5.

The population structure trend in $R S(Y)$ thousands of people as of the beginning of a year)

\begin{tabular}{|l|c|c|c|c|c|c|c|}
\hline $\begin{array}{c}\text { Age } \\
\text { category }\end{array}$ & 1990 & 2000 & 2005 & 2010 & 2014 & 2018 & $\begin{array}{l}\text { Increase } \\
(\text { loss })\end{array}$ \\
\hline UWA & $\begin{array}{c}356.2 \\
(32.0 \%)\end{array}$ & $\begin{array}{c}271.2 \\
(28.2 \%)\end{array}$ & $\begin{array}{c}238.2 \\
(25.0 \%)\end{array}$ & $\begin{array}{c}223.3 \\
(23.3 \%)\end{array}$ & $\begin{array}{c}229.9 \\
(24.1 \%)\end{array}$ & $\begin{array}{c}239.8 \\
(24.9 \%)\end{array}$ & $\begin{array}{c}-116.4 \\
(-32.7 \%)\end{array}$ \\
\hline WA & $\begin{array}{c}667.4 \\
(60.0 \%)\end{array}$ & $\begin{array}{c}597.0 \\
(62.0 \%)\end{array}$ & $\begin{array}{c}617.9 \\
(64.8 \%)\end{array}$ & $\begin{array}{c}613.1 \\
(64.0 \%)\end{array}$ & $\begin{array}{c}586.5 \\
(61.4 \%)\end{array}$ & $\begin{array}{c}560.2 \\
(58.1 \%)\end{array}$ & $\begin{array}{c}-107.2 \\
(-16.1 \%)\end{array}$ \\
\hline OWA & $\begin{array}{c}87.9 \\
(8.0 \%)\end{array}$ & $\begin{array}{c}94.3 \\
(9.8 \%)\end{array}$ & $\begin{array}{c}97.1 \\
(10.2 \%)\end{array}$ & $\begin{array}{c}122.1 \\
(12.7 \%)\end{array}$ & $\begin{array}{c}1385 \\
(14.5 \%)\end{array}$ & $\begin{array}{c}164.3 \\
(17.0 \%)\end{array}$ & $\begin{array}{c}+76,4 \\
(86.9 \%)\end{array}$ \\
\hline Total & $1,111.5$ & 962.5 & 953.2 & 958.5 & 954.8 & 964.3 & $\begin{array}{c}-147.2 \\
(13.2 \%)\end{array}$ \\
\hline
\end{tabular}

Thus, the main trends that have a negative impact on the creation of the workforce system in $\mathrm{RS}(\mathrm{Y})$ are as follows: the high MR of the working-age population of both sexes; the overmortality of working-age men; the prevalence of preventable causes of death of an exogenous nature (accidents, poisonings, injuries); and an increased share of retirement-age people, resulting in an increased demographic load on the able-bodied population.

\section{Conclusion}

The results obtained suggest that the population mortality pattern in Yakutia consists of a high proportion of losses from external causes in young age groups. In the structure of external causes of mortality, violent deaths and mortality from cold injury are of particular significance. The level of suicide mortality should still be considered critical, with the overall rate significantly exceeding the RF average. Moreover, the suicide rate in Yakutia is higher than the critical parameter defined by WHO experts as a threat to depopulation. The generally recognized negative impact of alcoholism on the crime situation in the region and on the level of social degradation in the society is obvious.

There is also an undoubted contribution of other factors of social deprivation on the level of violent deaths (low employment of the population and low-income level, lack of potential improvement of conditions, insufficient sociocultural development of the society, etc.).

The mortality of the population from the effects of cold temperature requires a separate study, since the data available do not allow us to establish reliable causes (workplace injuries, etc.) and the degree of its dependence on alcohol abuse. 
The data presented indicate a high degree of preventability of the causes of premature mortality in the republic and the availability of reserves for its actual reduction. The way for reducing preventable mortality in the region is primarily determined by decreased losses from external causes. To reduce the mortality from these causes, first, we should overcome poverty, reduce crime, develop wellthought-out and balanced anti-alcohol policies, and promote a healthy lifestyle.

$\mathrm{RS}(\mathrm{Y})$ is one of the regions of the Far Eastern Federal District with steady economic growth and intensive development of the social and cultural sphere. In the coming decades, the republic is going to witness large-scale socio-economic and cultural changes, due to the intensive development of natural resources, the introduction of industrial and post-industrial activities, and the entry into the global informational and cultural space. Global interests require an improved medical and demographic situation and stronger health of the population in $\mathrm{RS}(\mathrm{Y})$.

\section{Conflict of interest}

The authors declare that they have no competing interests.

\section{References}

1. Bykovskaia TIU, Piktushanskaia TE. [Regional patterns of the working-age men mortality under the modern conditions]. Meditsina truda i promyshlennaya ekologiya.2011;(2):28-33. [Article in Russian].

2. Ivanova AE, Semenova G, Antonova OI. Mortality in the regions of the Central District of Russia. In: Rybakovskii LL, IUr'ev EL, editors. Demographic development of the Central Federal District. Moscow: Ekon-Inform; 2016:86-198.

3. Rogovina AG. [Gender and settlement differentiation of mortality in Russiain2005-2012]. Biulleten'NNIIobshchestvennogo zdorov'ia RAMN.2014;(1):258-61. [Article in Russian].

4. Ivanova AA. The regional patterns of premature mortality of the population in the Sakha Republic (Yakutia). Abstract of ScD Thesis. Moscow; 2016. [In Russian].

5. Nemtsov AV. Alcohol damage in the regions of Russia. Moscow: Nalex; 2003. [In Russian]. 